\title{
COMPLEXES OF TREPYRIDINE AND THEIR DERIVATIVES AS LIVING SYSTEM ACTIVE COMPOUNDS
}

\author{
I. Rose Kumari ${ }^{1}$ and M. N. Sivakumar ${ }^{2, *}$ \\ ${ }^{1}$ Department of Science and Humanities, Saveetha Engineering College, \\ Saveetha Nagar, Thandalam, Chennai 602 105, India. \\ ${ }^{2}$ Department of Chemistry, AMET University Chennai 603 112, India \\ *E-mail: nitrosiva@gmail.com
}

\begin{abstract}
Ruthenium (II) mixed ligand mononuclear metal complexes containing 4'-(thiophene-2-yl)-2,2':6',2"-terpyridine (a tridentate ligand) and various bidentate ligands (1,10-phenanthroline, 1,10-phenanthroline-5,6-dione, 6,6'-dimethylbipyridyl, 4,4'-bipyridine-dicarboxylic acid, 4,4'-dimethyl-bipyridyl, bipyridyl, 1,10-phenanthroline-pyrazinephenanthrene fused planar ligand $\left(\mathrm{L}_{1}\right)$ ), and a chloride ligand and a binuclear ruthenium complex having 1,10phenanthroline-pyrazine-1,10-phenanthroline fused planar ligand $\left(\mathrm{L}_{2}\right)$ and 4'-(thiophene-2-yl)-2,2':6',2"-terpyridine ligands have been synthesized with fairly good yield using a modified literature procedure. All the eight complexes were precipitated as hexafluorophosphate salt from aqueous solution. These complexes were completely soluble in acetonitrile and sparingly soluble in water.
\end{abstract}

Keywords: ruthenium (II) mixed ligand, terpyridine, bidentate ligands, dicarboxylic acid, acetonitrile, hexafluorophosphate.

CORASĀYAN. All rights reserved

\section{INTRODUCTION}

Oligopyridines have attracted special interest in coordination chemistry. Although 2,2'-bipyridine (bpy) has been considered to be "the most used ligand in coordination chemistry"", 2,2':6',2"-terpyridine (tpy) also has a rich chemistry. The coordination chemistry of the substituted tridentate ligand has attracted the attention of many chemists ${ }^{2}$. The kinetics and mechanism of formation of metal complexes with these ligands and their stability have also been studied.<smiles>c1ccc(-c2cccc(-c3ccccn3)n2)nc1</smiles>

Scheme-1: Structures representing some complexes of $2,2^{\prime}$-bipyridine and $2,2^{\prime}: 6^{\prime}, 2^{\prime \prime}$ terpyridine with an octahedral metal center ( $X=$ substituted groups)

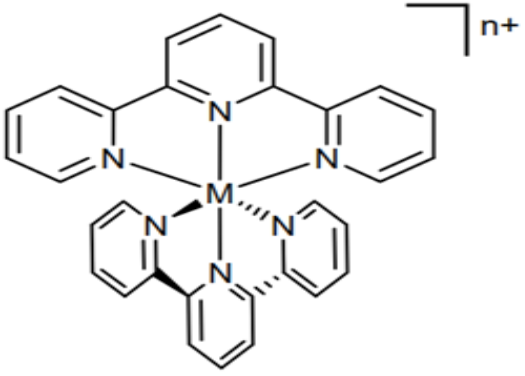

Scheme-2: (A) 2,2':6',2”-Terpyridine (Tpy) $\left[\mathrm{M}(\mathrm{tpy})_{2}\right]^{\mathrm{nt}}$

Rasayan J. Chem., 11(3), 1096 - 1102(2018)

http://dx.doi.org/10.31788/RJC.2018.1133010 
The tridentate polypyridyl ligand terpyridine (tpy (A)) is enjoying enormous and continuing popularity in supramolecular chemistry. This ligand forms very stable octahedral complexes with a wide range of metal ions (e.g., $\log \mathrm{K}$ for $\mathrm{Fe}(\mathrm{tpy})_{2}$ is $\left.>20\right)^{4}$ and has a major advantage over the bidendate analogue 2,2'bipyridine(bpy) unlike $\left[\mathrm{M}(\mathrm{bpy})_{3}\right]^{\mathrm{n}+}$ complexes, $\left[\mathrm{M}(\mathrm{tpy})_{2}\right]^{\mathrm{n}+}$ complexes are achiral (provided only symmetrical substitution of the tpy ligands are used) which becomes particularly important when considering multinuclear systems. The origin of this lack of chirality, which shows a $\left[\mathrm{M}(\mathrm{bpy})_{3}\right]$ center with a symmetrically substituted $\mathrm{M}(\mathrm{tpy})_{2}$ center. The former has two enantiomers $(\Lambda$ and $\Delta)$ as is the case for ideal octahedral metal complexes. However, in $\left[\mathrm{M}(\mathrm{tpy})_{2}\right]$, where three of the donor atoms are coplanar, the mirror images are super-imposable (the complex possess an inversion centre at the metal atom), rendering the complex achiral. The chirality can be introduced into $\left[\mathrm{M}(\mathrm{tpy})_{2}\right]$ complexes by attachment of chiral groups to the tpy ligand and several examples of the complexes are known. ${ }^{5}$

\section{EXPERIMENTAL}

\section{Methods for the Synthesis of TPY Ligands}

The two general methodologies used in the synthesis of 2,2':6',2"-terpyridines involve either the synthesis of the central ring (Scheme-3a) or the coupling of the three pyridine rings (Scheme-3b).

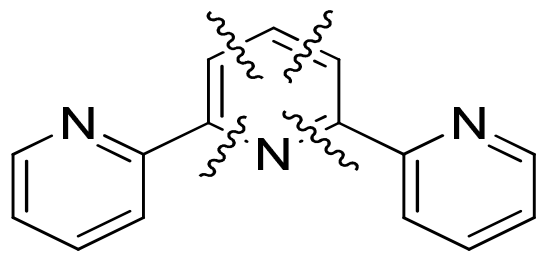

$3 \mathbf{a}$

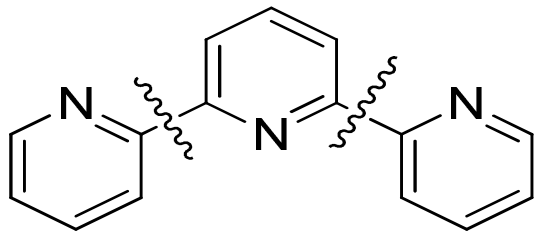

$3 \mathbf{b}$

Scheme-3a\&3b

From the synthetic point of view, there are only a few methods leading to this system which were known or have been developed during our work. While the Ullman coupling of bromopyridines is of historical interest, the main methodologies can be divided into the following categories: i) condensation methodology; ii) pyrolysis; iii) Tohda methodology; iv) metal mediated coupling reaction; v) cycloaddition (Sauer methodology).

Many attempts have been made to optimize the preparation of $2,2^{\prime}: 6^{\prime}, 2^{\prime \prime}$-terpyridine. ${ }^{6,7}$ One of the efficient methodologies for the synthesis of 2,2':6',2"-terpyridine was reported by Jameson and Guise. 2Acetylpyridine was reacted with $\mathrm{N}, \mathrm{N}$-dimethylformamide dimethyl acetal to give the enaminone. This enaminone was condensed with the potassium salt of 2- acetylpyridine with loss of dimethyl amine, the resulting 1,5-dione is not isolated prior to ring closure by ammonium acetate (Scheme-4).

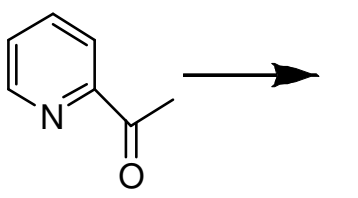

1<smiles>CN(C)/C=C/C(=O)c1ccccn1</smiles>

2<smiles>c1ccc(-c2cccc(-c3ccccn3)n2)nc1</smiles>

3

Scheme-4

\section{Krohnke Methodology}

Kröhnke has developed the methodology of condensation procedures leading to oligopyridines. ${ }^{8}$ The basis of this reaction is the aldol condensation of 2-acetylpyridine (or substituted derivatives) with an aldehyde in basic aqueous or alcoholic media to give an $\alpha, \beta$-unsaturated ketone or enone. A disadvantage is, however, that the substituents $\mathrm{R}_{2}$ must be aromatic (Scheme-5). Recently, this methodology was examined in solvent-free one-pot reactions for the synthesis of oligopyridines. 


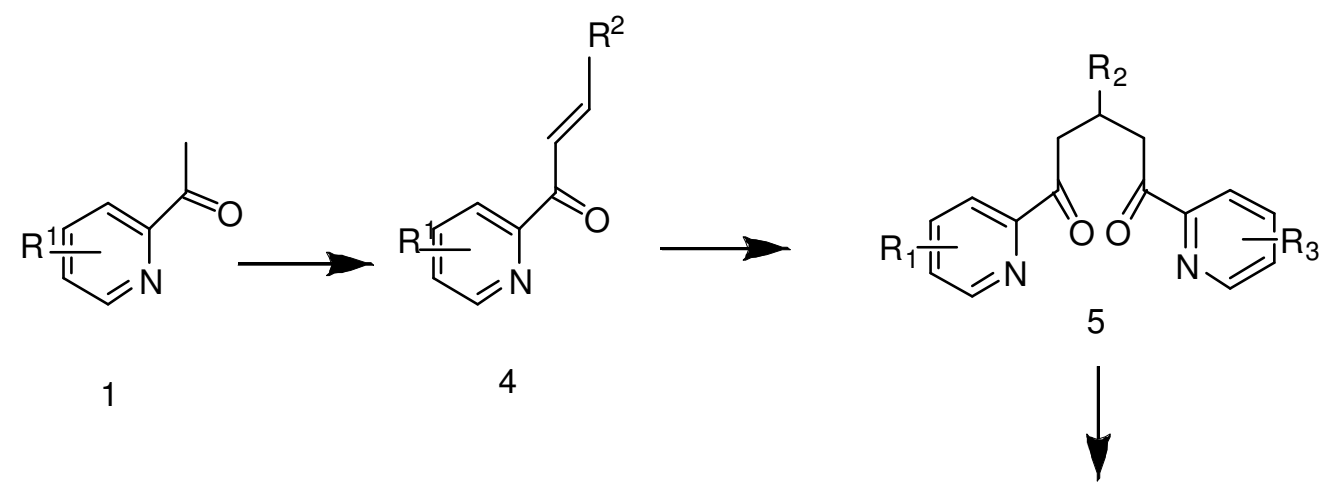

Potts Methodology<smiles></smiles>

6

Scheme-5

Potts and coworkers have also developed a methodology for the synthesis of substituted pyridines from the corresponding 1,5-dione and hydroxylamine. Though in many aspects similar to the Kröhnke methodology, this procedure has found wide applications in the synthesis of oligopyridines, especially when $\mathrm{C}\left(4^{\prime}\right)$ is substituted by a thiol group ${ }^{9}$ (Scheme-6).

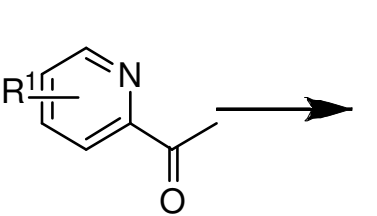<smiles>[R5]/C([Sb])=C/C(=O)c1cc[R1]cn1</smiles>

10<smiles>[R5]C(=CC(=O)C1=NC=C[R17]C=C1)CC(=O)c1cccnc1</smiles><smiles>[R5]c1cc(-c2cc[R7]([H])cc2)nc(-c2cccnc2)c1</smiles>

12

Scheme-6

\section{Synthetic Strategy of 4'-Functionalized Terpyridine}

4'-Functionalized terpyridines are versatile building blocks for supramolecular assemblies and polymers. The asymmetrically functionalized bipyridines (e.g.bipyridines bearing a substituent on one pyridine ring) 
RASĀYAN J. Chem.

Vol. 11 | No. 3 |1096 - 1102 | July - September | 2018

may lead to isomers ( $f a c$ or mertris(bipyridine) diastereomers), depending on the orientation of the functional groups ( $f a c$ or $m e r$ ) upon complexation with metal ions. The complexation of terpyridines leads to defined complexes because of a $4^{\prime}$-functionalized terpyridine possessing $C_{2 v}$ symmetry with a rotation axis through the 4'-position. Numerous examples are known for the reaction between 4'chloro(terpyridine) and alcohols in DMSO, using a base catalyst, e.g. $\mathrm{KOH}$ (Scheme-7). ${ }^{10}$<smiles>O=C(OCCNC(F)F)c1ccccn1</smiles>

13<smiles>CC(C)CC(N)=O</smiles>

14<smiles>[R]c1cc(-c2ccccn2)nc(-c2ccccn2)c1</smiles>

17<smiles>O=c1cc(-c2ccccn2)[nH]c(-c2ccccn2)c1</smiles>

15<smiles>[TeH3-][PbH3]</smiles>

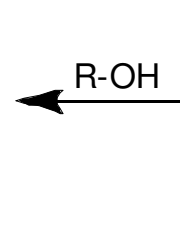<smiles>Clc1cc(-c2ccccn2)nc(-c2ccccn2)c1</smiles>

16

Scheme-7: A Synthetic approach to 4'-functionalized terpyridinesviathepyridone and chloro(terpyridine) route.

\section{Application of Metal Complexes}

\section{RESULTS AND DISCUSSION}

The study of the interaction between drugs and transition metal ions is an important and active research area in bioinorganic chemistry. It is well known that the action of many drugs depends on the coordination with metal ions and/or the inhibition on the formation of metalloenzymes. Therefore, metal ions might play a vital role during the biological process of drug utilization in the body. Terpyridine ligands and their metal complexes have gained a fair amount of notoriety since 2,2':6',2"'terpyridine was first synthesized by Morgan and Burstall in 1932. ${ }^{11,12}$ As a tridentate ligand, terpyridine is predisposed toward forming complexes of high thermodynamic and kinetic stability with a variety of transition metals. ${ }^{13}$ In addition, the straight forward synthesis of 4'-chloro-2,2':6',2'-terpyridine and its SNAr functionalization with various nucleophiles have resulted in the synthesis of a wide variety of substituted terpyridines, thus popularizing the use of the ligand in polymer functionalization and the production of self-assembled supramolecular structures. ${ }^{14-16}$

\section{Photochemical Activation Method and Drugs}

Photochemical activation is an elegant method to convert nontoxic prodrugs to active cytotoxic species in a spatially and temporally controlled manner. This provides a mechanism to discriminate between malignant tissues of tumors and the surrounding healthy tissues, potentially reducing the dose-limiting side effects incurred with standard chemotherapies. Photodynamic therapy (PDT) uses this light-targeted ap- proach, and has been successfully applied in the treatment of various cancers, notably of the lung, esophagus, and skin. ${ }^{17-20]}$

The photochemical activation of drugs is expected to have a significant impact in many fields of medicine including oncology. The use of light, which notably has led to the clinical development of photodynamic therapy (PDT) for the treatment of cancer and other diseases, offers the possibility to control the location, timing, and dosage of therapeutic compounds. An increased understanding of cancer at the molecular level has enabled the development of novel therapeutic agents that are sometimes referred to as 
molecularly targeted agents. Unlike the drugs used in conventional chemotherapy, these agents are designed to interfere specifically with key molecular events that are responsible for the malignant phenotype: they hold considerable promise for extending the therapeutic window and providing more effective treatment options when compared to traditional cytotoxic therapies. The transition metal complexes with DNA cleavage activities have attracted much attention because of their uses as DNA structure probes and as anticancer agents. Since the discovery that octahedral metal complexes with a dppz ligand $(\mathrm{dppz}=$ dipyrido[3,2-a:2',3'-c]phenazine) function as molecular "light switches" for DNA upon metal-to-ligand charge transfer (3MLCT) excitation, there has been much attention devoted to the biological activity of ruthenium(II) polypyridyl complexes, in particular in relation to the development of structure-specific DNA probes in living cells. On account of their unique photophysical responses to DNA, dppz complexes of ruthenium have been investigated ${ }^{21}$ widely and different modes of interactions of those complexes with DNA, via intercalation of the ligand or through direct covalent coordination of the electron-rich DNA bases with the metal center, have been revealed.

The cancer therapy is photodynamic therapy. In photodynamic therapy cells can be destroyed selectively by shining light of appropriate wave length. This way one can selectively destroy the cancerous cells. Drugs with potential application in photodynamic therapy should ideally have high excited state potential so that they can cleave DNA through photo-oxidation process. Alternatively, they must be able to generate singlet oxygen under photolytic conditions. Ruthenium complexes are ideally suited for photoprocess.

Ruthenium complexes are also better suited for medical applications because of their favorable rate of ligand exchange and their ability to mimic iron binding to certain biomolecules ${ }^{22}$. Dipyridyl complexes of ruthenium have been reported to show high excited state potential. However, these complexes are not very efficient DNA intercalators ${ }^{23}$. Phenanthroline complexes of ruthenium, on the other hand, are reported to bind DNA intercalatively ${ }^{24}$. As a resulting variety of ruthenium complexes with different phenanthroline derivatives have been synthesized and their DNA binding and cleaving abilities investigated ${ }^{25}$. On the other hand ruthenium complexes of terpyridine(tpy) ligands, which are more rigid compared to bidentatebipyridine ligands, have not been investigated systematically. The complexes of $2,2^{\prime}: 6^{\prime}, 2$ ' -tpy moieties have several synthetic and structural advantages over the bipyridine(bpy) complexes

\section{Photosensitizers for Photodynamic Therapy}

Cancer has arguably been one of the most studied diseases in the last 100 years. Despite enormous research efforts, cancer has caused over eight million casualties or $13 \%$ of all deaths worldwide in $2012 .{ }^{26}$ Thecorner stones of cancer therapy are radiotherapy, surgery, and chemotherapy. In the search for better approaches, photodynamic therapy (PDT) has proven to be a promising new, effective, and noninvasive chemo- therapeutic treatment modality. The general concept of PDT is based on a photosensitizer (PS), an ideally nontoxic molecule with a higher affinity for cancer cells over healthy cells that can be excited by irradiation with light and reach a triplet excited state through intersystem crossing. In this state, the PS can react with a substrate or solvent molecule (type I reaction), through hydrogen atom or electron transfer, generating radicals. The PS can also transfer energy to molecular oxygen (type II reaction), forming most prominently singlet oxygen The products of these two types of reactions are highly reactive and have been shown to cause severe cellular stress and to lead to apoptosis and/or necrosis. ${ }^{[45]}$ The advantages of PDT over other cancer therapies are the high spatiotemporal control and the low systemic toxicity of the treatment. Recently, PDT has also been investigated as a new remedy against bacterial infections. The application of antimicrobial PDT (aPDT) is intriguing because, unlike conventional antibiotics, aPDT does not have one specific target but instead affects multiple sites. This drastically decreases the incidence of resistance. In fact, resistance against aPDT has not been observed yet. With the imminent threat of widespread antibiotic resistance, aPDT could be a much needed new approach to fight the rapidly emerging, multidrug-resistant superbugs. Since the approval of the first PDT drug (porfimer sodium) in 1993, multiple (13 as of 2003) PDT PSs have reached the market. All of them are macrocyclic organic molecules, mostly porphyrin derivatives but also phtalocyanine- and chlorinbased molecules. These PSs share several drawbacks such as a cumbersome synthesis and purification, 
poor water solubility, and slow clearance, leading to prolonged photosensitivity in patients. There is, therefore, a need for novel PS with better photophysical and biological properties. The biological, chemical, and photolytic stability are key properties of a PS for potential PDT applications.

Photosensitizers are broadly classified into three groups, according to their mechanism of action. In all cases, the primary act is the absorption of light by the photosensitizer (PS), populating its singlet excited state, 1PS*. Type I and type II are two classes of mechanism of ROS/singlet oxygen generation, in both, PDT is initiated by an interaction of the photosensitizer in its excited state with oxygen, with the production of reactive oxygen species (ROS) including superoxide anion $(\mathrm{O} 2 \bullet-)$, hydroxyl radical $(\mathrm{OH} \bullet)$, or hydrogen peroxide $\left(\mathrm{H}_{2} \mathrm{O}_{2}\right)$, in type I, or singlet oxygen (type II), which then induce the damage leading to cell death. In the third class of mechanism of photo-activated cell death, which can be referred to as Photo-activated Chemotherapy (PACT), killing is initiated by a direct reaction of the photosensitizer in the excited state (or of products of its light-induced transformation) with biomolecules, leading to cell death that is independent of oxygen.

Coordination compounds of ruthenium(II) containing poly- pyridyl ligands have been the subject of a wide variety of photochemical studies directed toward their use as "photosen- sitizers" in photochemical molecular devices (PMDS). The complex tris(2,2'-bipyridine)ruthenium(II), [Ru(bpy)3I2+, is the archetype of such species and demonstrates the combined attributes of significant absorption in the visible spectral region, the relative longevity of the metal-to-ligand charge transfer (MLCT) excited states formed on light absorption, the relative inertness of the metal center in a variety of oxidation states, and the rapidity of the redox reactions involving the excited states.

\section{The Scope of the Present Investigation}

The complex $[\mathrm{Ru}(\mathrm{tpy})(\mathrm{bpy}) \mathrm{Cl}]^{+}$has been reported to have a labile $\mathrm{Ru}-\mathrm{Cl}$ bond. ${ }^{[74]}$ Ruthenium complexes are known for their unique characteristics of photostability. Our previous study on the effect on the photostability of ruthenium complexes. Ru(II) polypyridyl complexes with different 4'-substituted terpyridine shows that the mixed ligand complexes containing 4'-(thiophene-2-yl)-2,2':6',2"-terpyridine as a bidentate ligand shows good photolability based on the conductometry experiments and photonuclease activity. In order to see the complete ligand effect, in this study we have fixed the 4'-(thiophene-2-yl)$2,2^{\prime}: 6^{\prime}, 2^{\prime \prime}$-terpyridine as tridentate ligand and varied the bidentate ligands. And study their photophysical and electrochemical properties in order to exploit them for DNA cleaving, targeted drug delivery and photodynamic therapeutic applications. Hence the objectives of the investigation as follow:

1. Synthesis and purification of different derivatives of planar and nonplanar bidentate ligand.

2. Synthesis and characterization of 4'-(thiophen-2-yl)-2,2':6',2"-terpyridine ligand containing $\mathrm{Ru}(\mathrm{II})$ mixed ligand complexes with different bidentate ligands.

3. Study the photolabile nature of $\mathrm{Ru}-\mathrm{Cl}$ bond of various complexes using conductometry experiment.

4. Study their nature of binding with CT-DNA.

5. Investigate the ability of these complexes to cleave DNA photolytically and oxidatively.

\section{CONCLUSION}

The results obtained for the complexes at $72 \mu \mathrm{M}$ concentration in dark conditions and in the presence of $750 \mathrm{uM} \mathrm{H} \mathrm{O}_{2}$ are shown in figure 36. All these complexes 1-8 do not bring out any DNA cleavage in the dark condition, whereas all these complexes effectively cleave the DNA in the presence of $\mathrm{H}_{2} \mathrm{O}_{2}$. This clearly indicates that the reaction undergoes via Fenton's chemistry of reactive hydroxyl radical formation which destroys the DNA. The efficiency of the DNA cleavage in the presence of $\mathrm{H}_{2} \mathrm{O}_{2}$ by the complexes having a direct correlation with the ground state redox properties especially $\mathrm{E}_{1 / 2}$ values of the complexes.

\section{ACKNOWLEDGMENT}

We thank AMET University and Saveetha Engineering College for the financial support. We also thank the University of Madras for the biological studies. 


\section{REFERENCES}

1. A. Chaudhary, N. Bansal, A. Gajraj, and R. V. Singh, Journal of Inorganic. Biochemistry., 93, 393 (2003), DOI: 10.13140/2.1.4214.0169

2. S. Ilhan, H. Temel, I. Yilmaz, and M. Sekerci, Polyhedron.,26, 2795(2007), DOI: 10.1016/j.poly.2007.01.015

3. E. Bertolo, R. Bastida, W. De Blas, D.E. Fenton, C. Lodeiro, A. Macias, A. Rodrogues, and T. Rodriguez-blas, Journal of Include Phenom. Macro., 35,191(1999).

4. P. Guerriero, P. AVigato, D.E. Fenton, and P.C. Hellier, Acta Chem. Scand., 46, 1025(1992), DOI: $10.3891 /$ acta.chem.scand.46-102m

5. D. Parker, and J. A. G Williams, J. Chem. Soc. Dalton Trans., 3613(1996), DOI: $10.1039 / \mathrm{DT} 9960003613$

6. C. Piguet, and J.-C. G. Bunzli, Chem. Soc. Rev., 28, 347(1999), DOI: 10.1039/A804240C

7. P. Caravan, J. J. Ellison, T. J. McMurry and R. B. Laufer, Chem. Rev., 99, 2293(1999), DOI: $10.1021 / \mathrm{cr} 980440 \mathrm{x}$

8. G. Mathis, Clin. Chem., 41, 1391(1995).

9. I. Hemmila, T. Stalberg, and P. Mottram, Bioanalytical Applications of Labeling Technologies, Wallac-Oy: Turku, 1245(1995).

10. S. Comby, andJ.-C.G. Bnzli,.Handbook on the Physics and Chemistry of Rare Earths; Elsevier BV: Amsterdam, The Netherlands, 37, Chapter 235(2007)

11. P. Guerriero, S. Tamburini, and P.A. Vigato, Coord. Chem. Rev.,139, 17(1995)

12. Robertha C. Howell, Kirk V. N. Spence, Ishenkumba A. Kahwa, Andrew J. P. White and David J. Williams, J. Chem. Soc. Dalton Trans., 6, 961(1996), DOI: 10.1039/DT9960000961

13. R.O. Freire, G. B. Rocha and A. M.Simas, J. Mol. Model., 12, 373(2006), DOI: 10.1007/s00894-0050027-5

14. Bruker, APEX2, SAINT and SADABS. Bruker AXS Inc., Madison, Wisconsin, USA(2008), DOI: 10.1107/S2056989015010944/cq2016Isup2.hkl

15. L. Farrugia, J.J. Appl. Cryst., 30, 565(1997), DOI: 10. 1107 so0218

16. G. M. Sheldrick, Acta Cryst., 64, 112(2008), DOI:10.1107/S0021889811043202

17. A. Vijayaraj, R. Prabu, R. Suresh, C. Sivaraj, N. Raaman, and Narayanan, J. Coord. Chem., 64, 636(2011), DOI:10.1080/15533174.2015.1031040

18. K. Nakamoto, Infrared Spectra of Inorganic and Coordination Compounds, John Willey and Sons: New York, 244(1986), DOI:10.1002/bbpc.198800131

19. A. Bottcher, H. Elias, E.G. Jager, H. Langfelderova, M. Mazur, L. Muller, H. Paulus, P. Pelikan, M Rudolph and M Valko, Inorg. Chem., 32, 4131(1993), DOI: 10.1021/ic00071a028

20. M.L. Bhaumic, and M.A. El-Sayed, J. Phys. Chem., 69, 275(1965), DOI: 10.1021/j100885a042

21. W. Dawson and J. Kropp, M. Windsor, J. Chem. Phys., 45, 2410(1966), DOI: 10.1063/1.1727955

22. S. Aime, M. Bettinelli, M. Ferrari, E. Razzano and E. Terreno, Biochimica et Biophysica Acta, 7, 1385(1998), DOI: 10.1016/S0167-4838(98)00038-7

23. A. Vijayaraj, R. Prabu, R. Suresh, R. SangeethaKumari, V. Kaviyarasan, and V. Narayanan, Bull Korean Chem Soc., 33, 3581(2012), DOI:10.5012/bkcs.2012.33.11.3581

24. G.K. Bareford, G. M. Freeman and D. G. Erver, .Inorg. Chem., 86, 552(1986), DOI: 10.1021/ic00236a007

25. G. A. Bowmaker, J. P Williams, J. Chem. Soc. Dalton Trans., 23, 3593(1993), DOI: 10.1039/dt99300fx089

26. V. F. Alejandro, G.Y. Cristina, A.V. Jesffls and A.E. Miguel, Angewanda Chemical, 49, 4278(2010), DOI: 10.1002/anie.201004027

[RJC-3010/2018] 